\title{
Growth Accounting and Regressions: \\ New approach and results
}

Tiago Sequeira, Hugo Morão

REM Working Paper 0113-2020

January 2020

\section{REM - Research in Economics and Mathematics \\ Rua Miguel Lúpi 20, \\ 1249-078 Lisboa, \\ Portugal}

\section{ISSN 2184-108X}

Any opinions expressed are those of the authors and not those of REM. Short, up to two paragraphs can be cited provided that full credit is given to the authors. 


\title{
Growth Accounting and Regressions: new approach and results
}

\author{
Tiago Sequeira ${ }^{\mathrm{a}, \mathrm{b}, 1, *}$, Hugo Morão ${ }^{\mathrm{d}, 1,2}$ \\ ${ }^{a}$ Faculty of Economics, Universidade de Coimbra, Portugal \\ ${ }^{b}$ CeBER - Centre for Business and Economics Research \\ ${ }^{c}$ Lisbon School of Economics and Business, Universidade de Lisboa, Portugal \\ ${ }^{d}$ REM - Research in Economics and Mathematics
}

\begin{abstract}
We seek for determinants of the sources of growth. Using a growth accounting method that accounts for time variations in factor shares, we run growth regressions for a panel of 101 countries between 1950 and 2015. Our methodology takes into account the specific features of the data (namely outliers, heterogeneity, and cross panel correlations) and overcomes most criticisms previously raised on growth regressions. The most important evidence reveals that government current expenditure decreases the factor shares and has no effect on total factor productivity (TFP). Trade affects the TFP and the Biased Technical Change (BTC) components, decreasing the factor shares. Moreover, human capital decreases TFP and increases the BTC contribution to growth. This unveils the channels through which determinants of growth act in influencing economic growth.
\end{abstract}

Keywords:

Economic Growth; Growth Accounting; Growth Regressions; Time-varying shares; Government Expenditure; Robust estimation; Bootstrap

JEL: : O47, O50

\footnotetext{
${ }^{*}$ Corresponding author.

Email address: tiago.n.sequeira@fe.uc.pt (Tiago Sequeira)

${ }^{1}$ Tiago Sequeira acknowledges that CeBER has financial support from by Fundação para a Ciência e a Tecnologia.

${ }^{2}$ Hugo Morão thanks the support of University Lisbon. REM-UECE is supported by Fundação para a Ciência e a Tecnologia.
} 


\section{Introduction}

Production factor shares and economic growth are topics extensively analyzed in the literature. Solow (1956) provides the basis for the economic growth accounting method. One of the most debated issues is the importance of factors of production and technology as contributors to the economic growth rate and income.

In this study, as a first step, we apply a variable factor share methodology to obtain the shares of capital accumulation and technology across a broad cross-section of countries between 1950 and 2015. Then, as a second step, we use regression analysis to evaluate how instability, government expenditures, openness to trade, and human capital affect them. In that sense we are going beyond the crucial question 'why do some countries grow more than others?' In fact, we wish to ask 'why do some countries rely more on factor accumulation or on technology to grow?' While several lessons can be taken from the most robust (and recent) results on growth regressions, the reasons why some countries rely more on factor accumulation or technological change have been overcome by the literature.

In the regressions analysis, we base our methodology in the three seminal papers on clustering techniques (Cameron et al. (2008); Petersen (2009); Thompson (2011) $)^{3}$ to deal with common problems affecting the study of the relationship between growth and its determinants, thus facing the main criticisms that have been raised to the growth regressions literature, e.g. Sala-i Martin (1997). It is not rare to see cross-country studies tending to disregard heterogeneity and some possible interdependence across countries. ${ }^{4}$ In our estimations, we also deal with heterogeneity and extreme observations following recent contributions for panel data estimations. For example, Eberhardt and Teal (2011) presented substantial arguments to consider cross-country (common) effects when applying growth regressions. According to those authors, cross-border macroeconomic effects (e.g. common shocks such as financial or political crises) cannot be disregarded as has been doing in most of the cross-sectional country analysis. Also, Nakamura et al. (2017) show that when

\footnotetext{
${ }^{3}$ Double clustering methods are endorsed by these three papers as a way to handle persistent shocks in both time and cross-sectional dimensions which are the main source of reverse causality and omitted variable bias in cross-country regression.

${ }^{4}$ Many studies simultaneously handle country and time-period effects employing dummies even though this procedure has limitations. Both fixed-effects have problems in dealing with complex error structures. Country-dummies do not accurately model the autoregressive process, and timeperiod dummies do not capture some specific country dynamics. Second, the use of dummies restricts the number of covariates that can be used due to collinearity with other regressors and country-dummies inflate the standard errors when the covariates do not vary much across timeperiods (see, e.g. Thompson (2011)).
} 
estimating growth regressions in panel data it is crucial to consider both countryspecific and worldwide effects, and serious biases will emerge if we fail to take them into account, suggesting, e.g., statistical significance where it does not exist. Second, Thompson (2011) suggests the use of robust standard errors estimation in panel models where the errors and regressors have both time and country effects and persistent idiosyncratic shocks that affect different countries in different time periods. We use robust standard-error in line with the computational contributions of Millo (2017). Third, another of the main criticisms of empirical works using cross-section growth regressions points for neglected extreme observations which generate weak and dubious economic inference (Kaffine and Davis, 2017; Easterly, 2005). To tackle this problem we include the Cribari-Neto and da Silva (2011) weighting function in our covariance estimation, which surpasses the other methods in the presence of very influential observations. Finally, we further deal with individual heterogeneity that is potentially correlated to the regressors.5

Our contribution is twofold. First, we offer an empirical explanation, not for economic growth itself but the contributions of capital - physical and human - and TFP to economic growth. In that sense, we contribute to answering the question 'why the growth of countries relies more on capital accumulation or productivity?' Second, we deal with most of the main criticisms raised against the growth regressions methodology. In that sense, this paper also relates to the contributions of Brock and Durlauf (2001); Durlauf (2005); Ley and Steel (2009); Sala-i Martin (1997). All these papers criticize traditional growth regressions questioning their usefulness to obtain lessons for the understanding of economic growth or design policy. Some of them also suggest some ways to improve their inference properties. In this paper, we apply alternative econometric approaches developed recently (Thompson, 2011, Cribari-Neto and da Silva, 2011; Millo, 2017) to address these issues.

The most crucial evidence from our empirical exercise reveals that current government expenditure (as a ratio to GDP) decreases the factor shares and has no effect on total factor productivity (TFP), highlighting significant long-run crowdingout effects or Ricardian-like intertemporal effects. Trade, however, affects the TFP and the Biased Technical Change (BTC) components, tending to decrease the factor shares. Moreover, human capital decreases the TFP contribution but increases the BTC contribution to growth. More deeply rooted determinants of development, such as ethnic diversity and historical population density, also affect factor accumulation, TFP, and BTC in different ways. Finally, the temperature tends to raise the labor share and decrease the TFP component.

\footnotetext{
5 Kelly (2019) surveys issues of persistence in error structure.
} 
In what follows, in section 2, we briefly review the related literature. In Section 3. we applied the growth accounting methodology and constructed the variables. In Section 4 , we present the growth regression method for the factor shares and technology obtained in the previous section and present our results. In section 5 , we conclude.

\section{Literature Review}

In this section, we briefly review the literature on growth accounting and the related constant shares issue 6

In influential articles, Hall and Jones (1999) and Easterly and Levine (2001) concluded that the most important source of growth is the total factor productivity (TFP). In particular, Hall and Jones (1999) presents evidence according to which differences in TFP rely on institutional differences among countries. However, growth accounting has been implemented assuming constant factor shares, following the well-known Kaldor stylized fact for the US. However, many recent studies (e.g., Zuleta (2008)) conclude that factor shares vary across years and countries. This new evidence implies that the growth accounting methodology should be adapted. As an exception to the use of constant factor shares, Sturgill (2014) analyzes development accounting with variable factor shares using translog multilateral indices of outputs, inputs, and productivity. The results reveal that the correction for the mismatch between physical capital and its share reduces the variation in output per worker. Although Keynes (1939) and Solow (1957) already expressed the doubt about the constancy of shares, most of the growth researchers continued arguing that constancy of factor shares is a stylized fact of Macroeconomics (e.g., Kaldor (1961)). Literature uses this stylized fact in both exogenous and endogenous growth theories, without much questioning of its empirical validity, and especially in growth accounting applications - see, e.g., Barro (1999).

Kahn and Lim (1998) shows evidence that the income shares of equipment, production workers, and non-production workers have clear trends. Blanchard (1997) observes that the share of labor decreases in Europe after the 1980s and argues that the reason for the decline is the technological bias. Some other authors calculated the income share of reproducible factors, like human and physical capital, and nonreproducible factors, and showed evidence according to which the latter is correlated positively with the income level (Krueger, 1999; Caselli and Feyrer, 2007). Follow-

\footnotetext{
${ }^{6}$ This does not aim to be an extensive review of the also vast growth accounting literature but a directed review to the issues that we are dealing with in this article.
} 
ing the same line, Sturgill (2012) decomposed the labor' share into reproducible and non-reproducible components with cross-country estimates and found that the labor' share correlates negatively with output per worker.

Despite the interest in biased technological change raised by the seminal work of Acemoglu (2002), there have been few attempts to correct the standard measure of the total factor of productivity (TFP) to the existence of biased technological change. In the US, there is some evidence that technology has favored skilled workers since the 1980s in manufacturing (Mallick and Sousa, 2017).

Since the seminal article from Barro (1991), growth regressions have seen exponential applications seeking to assess the most important determinants of economic growth. The so-called Barro regressions highlighted positive factors associated with growth, such as investment in physical and human capital, openness to trade, and negative factors associated with growth, such as the government weight in the economy and distortions in the market (e.g., the black market exchange rate premium). Additionally, Easterly and Rebelo (1993) positively associated public investment in transport and communication with growth. Corruption was found to deter investment (e.g. Ades and Di Tella (1997)). Macroeconomic factors like inflation and budget deficits also have a role in growth by reducing both capital accumulation and TPF growth as in Fischer (1993). Financial market development has a positive association with growth (see Levine (1997) and Levine (2005) for important surveys). More institutional, historical, and geographical factors associated with growth have been highlighted by Easterly and Levine (2003). However, outliers are the main driver of many big policy effects exposed in growth regressions because they typically represent policy failures (Easterly, 2005). As stated in Bertrand et al. (2004), only a small number of empirical studies using panel methods have employed clustered standard errors to deal with that problem.7

\section{Growth Accounting}

In this section, we analyze the panel data collected from 1950 to 2015 for 101 countries 8 The only selection criterion used was data availability for the most extended period. All variables are quinquennial to avoid short-run oscillations, usually related to business cycles.9 The data are from Penn World Tables (PWT 9.0). The

\footnotetext{
${ }^{7}$ We discuss the technical problems pointed out to the growth regressions methodology in the Introduction.

8 Appendix A.1 provides a list.

${ }^{9}$ Our approach crucially differs from the one used in Zuleta and Sturgill (2015). While they use cross-sectional data for a specific period, we use richer panel data and correct the estimates for
} 
Zuleta (2012) approach creates four growth shares assuming, contrary to the usual growth accounting method, variations in the capital and labor shares. The outcome variables are Capital, Labor, TFP, and Biased Technological Change shares.

\subsection{Applying the Growth Accounting Methodology}

First, the the production function (with all the standard assumptions) is the following:

$$
Y_{t}=A_{t} F\left(\theta_{k} K_{t}, \theta_{l} L_{t}\right)
$$

where $Y_{t}$ is output-side real GDP at current PPPs (in millions of 2011US\$), $K_{t}$ is capital stock at current PPPs (in millions of 2011US\$), and $L_{t}$ is number of persons engaged (in millions). Factor efficiency is measured by $\theta_{k}$ and $\theta_{l}$ for capital and labor, respectively. The economy is labor abundant when $\theta_{l} L_{t} \geq \theta_{k} K_{t}$. 10

Differentiating 1 we get:

$$
g_{y}=\left[g_{a}+\alpha_{t} g_{k}+\left(1-\alpha_{t}\right) g_{l}+\Delta \alpha_{t} \ln \left(\frac{\theta_{k} K_{t}}{\theta_{l} L_{t}}\right)\right] .
$$

The output elasticity with respect to labor is $\left(1-\alpha_{t}\right)$ and $\alpha_{t}$ is the elasticity of output with respect to labor 1 The traditional Solow residual $\left(g_{a}\right)$ is the following:

$$
g_{a}=g_{y}-\left(\alpha_{t} g_{k}+\left(1-\alpha_{t}\right) g_{l}\right) .
$$

The Solow residual from 2 and 3 also contains biased technological change (BTC) toward physical capital, which is measured by the term $\ln \left(\frac{\theta_{k} K_{t}}{\theta_{l} L_{t}}\right)$. The higher the productivity of physical capital when compared to productivity of labor, the more biased technical change will be towards physical capital.

$$
S_{t}=g_{a}+\Delta \alpha_{t} \ln \left(\frac{\theta_{k} K_{t}}{\theta_{l} L_{t}}\right) .
$$

both persistent temporal and common shocks in the error structure and seeks to minimize potential endogeneity issues using recent seminal clustering methods. These are econometric issues that Zuleta and Sturgill (2015) do not approach.

${ }^{10}$ The annual compound output growth rate is $g_{y}=\left(\frac{r g d p o_{n}}{r g d p o_{n}-1}\right)^{(1 / 5)}-1$, the annual compound growth rate of physical capital and labor are respectively, $g_{k}=\left(\frac{c k_{n}}{c k_{n-1}}\right)^{(1 / 5)}-1$ and $g_{l}=\left(\frac{e m p_{n}}{e m p_{n-1}}\right)^{(1 / 5)}-1$.

${ }^{11}$ This relies on the standard literature assumption that factor markets are competitive at the macroeconomic level and technology is labor-augmenting. 
Using the expression $\tilde{S}_{t}=S_{t}-\Delta \alpha_{t} \ln \left(\frac{K_{t}}{L_{t}}\right)$ we obtain $\tilde{S}_{t}$ as:

$$
\tilde{S}=g_{a}+\Delta \alpha_{t} \ln \left(\frac{\theta_{K}}{\theta_{L}}\right) .
$$

Again in equation (5) the higher the relative productivity of physical capital to labor, the more biased technical change will be towards physical capital .Then,

$$
\tilde{S}=C_{0}+C_{1} \Delta \alpha_{t}+\eta_{t}
$$

where $g_{a}=C_{0}+\eta_{t}$ and $C_{1}=\ln \left(\frac{\theta_{K}}{\theta_{L}}\right)$.

12

$$
g_{y}=\left(\alpha_{t} g_{k}+\left(1-\alpha_{t}\right) g_{l}+g_{a}+\Delta \alpha_{t} C_{1}\right.
$$

Figure 11 shows an example of the data we obtain after the application of the growth accounting methodology described above - for low and high-income countries.

The right-hand side of equation (7) is an algebraic sum of (i) the physical capital share $\left(k_{-}\right.$comp $)-\alpha_{t} g_{k}$, (ii) the labor share $\left(l_{-}\right.$comp $)-\left(1-\alpha_{t}\right) g_{l}$, (iii) the total factor productivity (TFP or $a_{-}$comp) $-g_{a}$, and (iv) the biased technical change $($ BTC or btc_comp $)-\Delta \alpha_{t} C_{1}-$ shares, respectively.

\subsection{Data}

In this section we analyze the components (or shares) of the growth decomposition, as follows: $k_{-}$comp - Physical Capital Component; $l_{-}$comp - Labor Component; $a_{-}$comp - Total Factor Productivity Component; btc_comp - Biased Technological Change Component.

Figure 1 shows an example of the data we obtain after the application of the growth accounting methodology described above - for low and high-income countries 13

\footnotetext{
${ }^{12}$ Clustered standard-errors as described in the introduction have been applied - see e.g. Cameron et al. (2008); Petersen (2009); Thompson (2011).

${ }^{15}$ Figures for other groups of countries are available upon request.
} 
Figure 1: High and Low Income Countries

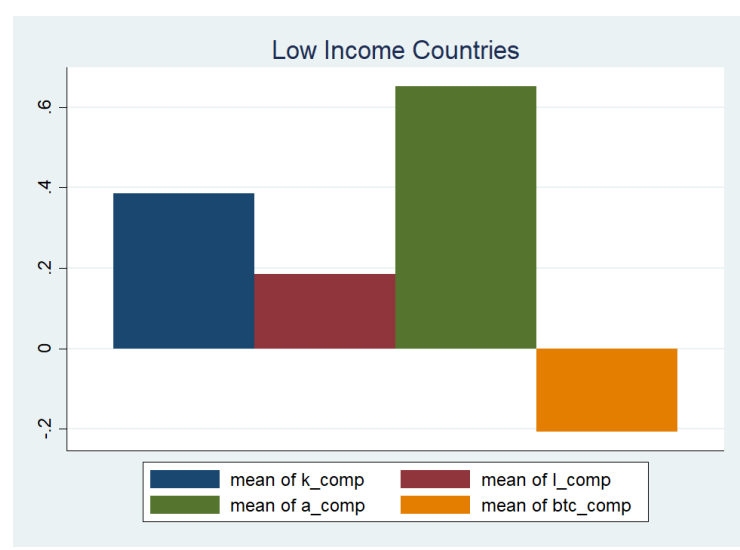

Note: Bar charts created using Stata.

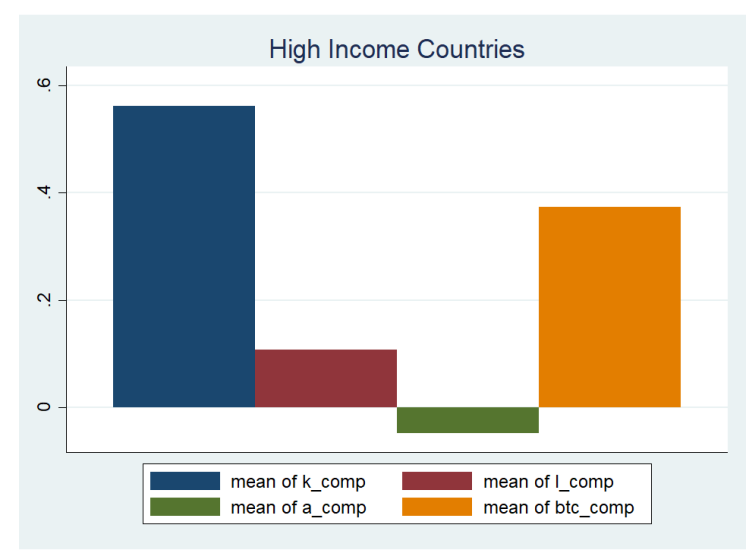

Note: Bar charts created using Stata.

Lower-income countries obtained their growth gains from productivity growth and capital accumulation. The harmful biased technological component may be explained by a brain drain effect that is implied by the migration of highly productive workers to rich countries. In rich countries, we can visualize the meager contribution of productivity (which may be associated with the process of productivity slowdown in developed countries - see, e.g., Sequeira et al. (2018) - and the improvements occurring from the labor and capital contributions, as well as a positive biased technical change contribution.

\section{Growth Regressions}

In this Section, we present the specification and results of the regressions for the shares of different factors of production and biased technical change and total factor productivity contributions.

\subsection{Regressors}

Economic growth has been reported to be inversely related to the government current expenditure (as a ratio to GDP), meaning that lower government consumption enhances growth - see, e.g., Barro (1997). Pritchett and Aiyar (2015) presents evidence according to which this relationship is especially strong in developing countries. The contribution of the government expenditures or debts to growth has become particularly controversial following the now-famous contribution of Reinhart and Rogoff (2010). However, in most growth regressions, the current government expenditure (as a ratio to GDP) appears with a negative and significant 
sign. With our results, we will be able to tell which component of growth is more affected by government expenditures, and in this case, where the negative sign comes from if it exists.

Openness (trade) is obtained by summing exports and import shares. The relationship between openness and economic growth has been regarded as positive in the literature (Yanikkaya (2003)). In developing countries, increased trade openness does not necessarily increase wages, while in developed countries, wage earners will, in general gain in the medium run with increased trade - see Majid (2004).

In general, and despite some initial controversy (Benhabib (1994)), the most recent empirical literature confirms that Human capital is positively related to growth ( Sunde and Vischer (2015); Teixeira and Queirós (2016)).

Guerrila warfare (gwar) is used as a proxy for political and social instability, as higher degrees of instability are correlated with lower growth rates (Alesina et al. 1996), because it also lowers the rates of overall productivity growth as pointed out by Aisen and Veiga (2013).

Additionally, we have included three time-invariant regressors that improve explanatory power by adding some geographical factors. Ashraf and Galor (2012) show that Population density in $\mathbf{1}$ CE (pd1) embodies some significant economic development effects for countries that have long lifetimes. The Middle East and Central Asia were the regions with the highest density because the first large civilizations emerged there. Some literature has examined the association between average Temperature (temp) and aggregate economic variables using panel data. The central relationship found was a reduced economic growth rate and a lower level of output, but the effects are only substantial in emerging countries - see Dell et al. (2012). Ethnic Diversity (ethnic) tends to lower a country's economic growth rate because higher levels of ethnic fractionalization are related to unstable regimes, as is shown in Easterly and Levine (1997) and Alesina et al. (2003).

\subsection{Descriptive Analysis}

The descriptive statistics (see Table 1) show that we have a very diversified unbalanced panel of countries: more than 70 countries with thirteen 5-year periods make this a very good sample, comparing to to the available empirical growth studies. The panel data for $c s h \_g$, trade and $h c$ were extracted from Penn World Tables 9.0 (PWT) - Feenstra et al. (2015), gwar from databanks database (cross-national time-series data archive - CNTS, Banks and Wilson (2019)) and temp, pd1 and ethnic from Geographically based Economic data (G-Econ) - Nordhaus (2006). For a better view on variables, sources and references are in the Appendix A.1. 
Table 1: Descriptive statistics

\begin{tabular}{lllllll}
\hline Variables & $\boldsymbol{A R}(\mathbf{1})$ & $\boldsymbol{C S D}$ & Mean & S.D. & Min & Max \\
\hline K_share & $3.47^{*}$ & $31.29^{* * *}$ & 0.677 & .5692 & -3.599 & 2.272 \\
L_share & $8.77^{* * *}$ & $7.81^{* * *}$ & 0.435 & .5856 & -2.736 & 2.338 \\
A_share $_{\text {_t_C_share }}$ & $3.86^{*}$ & $2.98^{* * *}$ & 0.218 & .9210 & -3.242 & 4.111 \\
BTC_. & 1.26 & 0.096 & .6609 & -3.377 & 3.239 \\
csh_g & $169.3^{* * *}$ & $34.9^{* * *}$ & 0.179 & .0840 & .0324 & .6342 \\
trade & $99.46^{* * *}$ & $8.56^{* * *}$ & -0.034 & .0989 & -.5745 & .3612 \\
hc & $6121.83^{* * *}$ & $110.22^{* * *}$ & 2.269 & .7158 & 1.009 & 3.719 \\
gwar & $3.49^{* * *}$ & 1.74 & 0.402 & 2.663 & 0 & 60.2 \\
pd1 & & & 3.176 & 4.403 & .011 & 23.80 \\
temp & & & 16.60 & 8.764 & -7.929 & 28.64 \\
ethnic & & & 0.418 & .2490 & .012 & .887 \\
\hline
\end{tabular}

Note: $\mathcal{H}_{0}$ of Pesaran Test: Variable is cross sectional independent. $\mathcal{H}_{0}$ of Wooldridge Test: Variable follows an $\operatorname{AR}(1)$ process. ${ }^{* * *} p<0.01,{ }^{*} p<0.1$. The Stata commands xtserial, xtcd2 and xtsum were used to reach the table. There are 719 observations in the sample, covering 71 countries, with a T-bar of 10.127 .

\subsection{Estimation}

In this subsection, we describe our estimation steps that will handle with the various issues stated in the introduction.

\subsubsection{Model Specification}

We consider the following panel regression:

$$
y_{i t} \equiv \mu+v_{t} \gamma+\zeta_{i t} \psi+\varepsilon_{i t} \equiv X^{\prime} \beta+\varepsilon
$$

with the coefficients vector

$$
\beta_{K, 1}=\left(\begin{array}{c}
\mu \\
\gamma \\
\psi
\end{array}\right)
$$

and $y_{i t}$ the dependent variable - the production factor component or TFP. $X$ is a vector of covariates and $\varepsilon_{i t}$ is a vector of error terms that can be heteroskedastic but with zero conditional mean, thus $E\left(\varepsilon_{i t} \mid \zeta_{i t}\right)=0$. Index $i$ refers to countrylevel observations and $t$ to periods in which $i=1, \cdots N$ countries observed over $t=1, \cdots, T$ periods.

Equation (9) error term $\varepsilon_{i t}$ and the regressors $\zeta_{i t}$ contain three components: $\bar{\varepsilon}_{i}$ and $\bar{\zeta}_{i}$ represent country-specific effects; $\varsigma_{t}$ and $\varkappa_{t}$ are both vectors of autocorrelated 
common factors that follow an $A R(1)$ process; $\phi_{i}$ and $\delta_{i}$ represent vectors of idiosyncratic factor sensitivities that follow a distribution $\mathcal{N}(0,1)$. Finally, $\omega_{i t}$ and $\xi_{i t}$ are the idiosyncratic errors, as follows.

$$
\varepsilon_{i t}=\bar{\varepsilon}_{i}+\phi_{i} \varsigma_{t}+\omega_{i t} \quad \text { and } \quad \zeta_{i t}=\bar{\zeta}_{i}+\delta_{i} \varkappa_{t}+\xi_{i t}
$$

If $\varsigma_{t}$ is uncorrelated across time periods we are in presence of the time effects, but when $\varsigma_{t}$ is persistent we have both time-period effects and persistent common shocks. This error structure strictly follows the advices in Eberhardt and Teal (2011) to adress endogeneity bias induced by heterogeneity.

\subsubsection{Assessing assumptions}

The error term includes unobserved components like country-specific effects and shocks that are common and persistent that affect all countries. Thus, checking for possible violations of assumptions is vital since our main objective here is to minimize the biases stated in section 1. If some of the assumptions are violated, a robust standard error estimator will be required. To that end, we performed a set of tests on standardized residuals.

Table 2: Lagrangian multiplier test of independence

\begin{tabular}{ccccc}
\hline & K_share & L_share & A_share & BTC_share \\
\hline Statistics & $\chi^{2}(1)=0.00$ & $\chi^{2}(1)=9.28^{* * *}$ & $\chi^{2}(1)=0.69$ & $\chi^{2}(4)=0.00$ \\
\hline Note: ${ }^{* * *} p<0.01 . \mathcal{H}_{0}$ of LM Test: $\mathbb{V}(u)=0$. The Stata command used was xttesto.
\end{tabular}

The Langragian multiplier test of independence was performed to verify if the variance across countries is $0 . \mathcal{H}_{0}$ is rejected for $L_{-}$comp which means that a random effects estimation is the correct approach; for all the others component a pooled estimation is the best option.

Table 3: Breusch-Pagan and Doornik-Hansen Tests

\begin{tabular}{|c|c|c|}
\hline & Homoskedasticity & Normality \\
\hline Statistics & $\mathcal{F}(1,749)=901.72^{* * *}$ & $\chi^{2}(2)=1014.98^{* * *}$ \\
\hline
\end{tabular}

We also assess the normality of the residuals as non-normal errors distort p-values and confidence intervals. The existence of heteroskedasticity was checked using the 
BP test enhanced by an F-statistic version that drops the normality assumption. The rejection of $H_{0}$ indicates that the residuals suffer from heteroskedasticity. Heteroskedastic residuals require a robust standard error estimation.

Table 4: Pesaran and Wooldridge Tests

\begin{tabular}{c|cc}
\hline \multirow{2}{*}{ Equation } & Spatial Correlation & Serial Correlation \\
\hline$K_{-}$share & $\mathcal{N}(0,1)$ & $\mathcal{F}(1,70)$ \\
$L_{-}$share & $11.347^{* * *}$ & $2.915^{*}$ \\
$A_{-}$share & 1.237 & $8.746^{* * *}$ \\
BTC_share & $3.592^{* * *}$ & $3.843^{*}$ \\
\hline
\end{tabular}

Note: ${ }^{* * *} p<0.01,{ }^{*} p<0.1$. $\mathcal{H}_{0}$ of Pesaran Test: Errors are cross sectional independent. $\mathcal{H}_{0}$ of Wooldridge Test: Errors do not follow an AR(1) process. The Stata commands used were $\mathrm{xtcd} 2$ and $\mathrm{xtserial.}$

The Cross-Dependence test detected cross-sectional dependence, which would originate omitted-variables bias when the regressors are correlated with the unobserved common factors. This type of correlation may appear when countries or regions share common shocks, as we mention above - see Eberhardt and Teal (2011). The literature identifies two types of dependence when there is broad global interdependence in the panel - see, e.g., Moscone and Tosetti (2010) and spatial dependence - see, e.g., Anselin (2001). Government consumption, Human capital, and Trade have relevant correlated common shocks between cross-sections. To check the existence of an $\mathrm{AR}(1)$ process in the error terms, we perform a serial correlation that confirmed the existence of autocorrelation. This calls for the error structure presented above in equation (8).

\subsubsection{Assessing model structure}

First, we test the proposed model for omitted and redundant variable bias.

Table 5: RESET, Link and VIF Tests

\begin{tabular}{|c|c|c|c|}
\hline & Omitted Variables & Redundant Variables & \\
\hline Statistics & $\mathcal{F}(3,740)=0.66$ & $\mathcal{N}(0,1)=0.13$ & Mean $\mathrm{VIF}=1.36$ \\
\hline
\end{tabular}

The RESET Test check if we omitted some relevant variables in the specification process, which was not the case. Linktest is a specification test that verifies the 
existence of redundant variables that can warm the quality of the estimation by biasing the regressors, which also validate our specification. Multicollinearity might be problematic when the VIF and condition number are greater than 10, because it means that some regressors are closely correlated to one another', biasing the standard errors, distorting confidence intervals, and providing less reliable probability values. Meager condition numbers and VIF support the absence of multicollinearity.

\subsubsection{Important group of observations}

In the literature, one of the main concerns about validity is the presence of outliers. Rousseeuw and Leroy (2003) shows that some of the vertical outliers and bad leverage points are especially problematic. Vertical outliers affect the estimated intercept since the observations have outlying values for the residuals, whereas bad leverage points are observations that have outlying values but are far away from the regression line.

We used a graphical tool to check this issue. This is done by plotting, on the $Y$-axis, the robust standardized residuals, as $r_{i} / \hat{\sigma}^{S}$, with $\hat{\sigma}^{S}$ being a measure of dispersion, robust against extreme values making the residuals less sensitive to these values and 'outlyingness' in the fitted regression. On the $X$-axis we plot the Mahalanobis distance, which measures outlyingness of the explanatory variables. There are several ways to measure robust Mahalanobis distance, but the most robust (which we used) is an algorithm that uses a minimum covariance determinant.

We set the limits proposed by Verardi and Croux (2009), where outside the observations are measured as outliers. 
Figure 2: Diagnostic plot of standardized robust residuals versus robust Mahalanobis distance

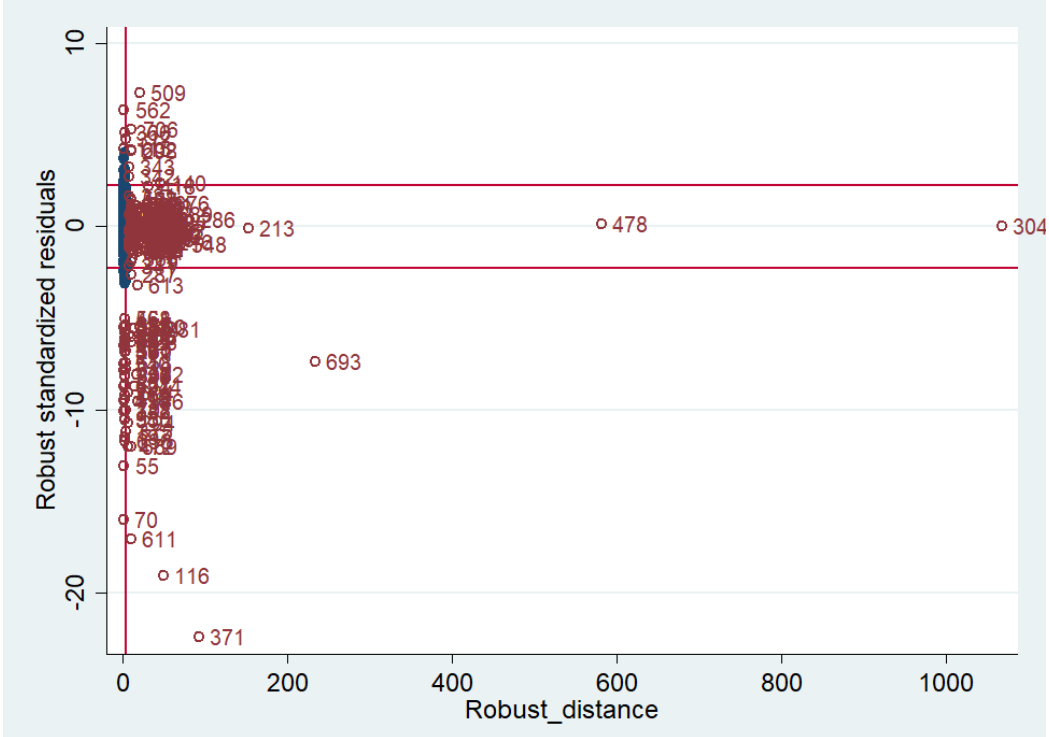

Note: Note: Tests only executed for K as Dependent variable. The Stata command used was collin.

This plot shows that we have some outliers in our dataset, which means that leverage points need to be accounted for ${ }^{14}$ Table 6 summarizes the diagnostic summary for each of the dependent variables and, consequently, the necessary care to take in each of the regressions presented below.

Table 6: Errors diagnosis sum up

Panel

SEs need to be robust against

$K_{-}$comp overleverage, arbitrary heteroskedasticity, within-panel autocorrelation and cross-panel autocorrelated disturbances.

L_comp overleverage, arbitrary heteroskedasticity and contemporaneous cross-panel correlation.

$A_{-}$comp overleverage, arbitrary heteroskedasticity, within-panel autocorrelation and

$B T C_{\_}$comp overleverage and arbitrary heteroskedasticity.

Note: Arbitrary heteroskedasticity is tested in 3 overleverage and outliers were checked in 2 within-panel autocorrelation and cross-panel autocorrelation is tested in 4

\footnotetext{
${ }^{14}$ Another two visual tests using Studentized residuals and the leverage statistic reach similar conclusions. They are available upon request.
} 


\subsubsection{Cluster-robust and kernel-robust standard errors}

As a result of the last sections and Table 6, we need to address the violation of distribution and correlation of error assumptions to assure good statistical inference. In the presence of violated assumptions, we use alternative ways to compute covariances matrix estimators to obtain robust standard errors. We made three error correlation assumptions. First, $\varepsilon_{i t}$ have country-effects when $\varepsilon_{i t}$ is correlated across time periods for a specific country $E\left(\varepsilon_{i t} \varepsilon_{i k} \mid x_{i t}, x_{i k}\right) \neq 0$. Second, time-period effects are present at some moment in time, meaning that there is correlation between countries, $E\left(\varepsilon_{i t} \varepsilon_{j t} \mid x_{i t}, x_{j t}\right) \neq 0$. Lastly, when, $E\left(\varepsilon_{i t} \varepsilon_{j k} \mid x_{i t}, x_{j k}\right)=0$ if $i \neq j$ and $|t-k|>\ell$, we are in the presence of persistent common shocks that disappear after $L$ lags.

Table 7: Error and regressors correlation assumptions

\begin{tabular}{llllllllll}
\hline & \multicolumn{3}{l}{ Errors } & & \multicolumn{4}{c}{ Regressors } \\
\hline & $K$ & $L$ & $A$ & $B T C$ & $z 1$ & $z 2$ & $z 3$ & $z 4$ \\
\hline Country-Effects & $\mathrm{X}$ & $\mathrm{X}$ & $\mathrm{X}$ & $\mathrm{X}$ & $\mathrm{X}$ & $\mathrm{X}$ & $\mathrm{X}$ & $\mathrm{X}$ \\
Time-Effects & $\mathrm{X}$ & $\mathrm{X}$ & $\mathrm{X}$ & & & $\mathrm{X}$ & $\mathrm{X}$ & $\mathrm{X}$ & $\mathrm{X}$ \\
Persistent common shocks & $\mathrm{X}$ & & $\mathrm{X}$ & & & $\mathrm{X}$ & $\mathrm{X}$ & $\mathrm{X}$ & \\
\hline S.E. type & $\vartheta$ & $\varrho$ & $\vartheta$ & $\varpi$ & & - & - & - & - \\
\hline
\end{tabular}

Notes: $\vartheta$ stands for Thompson (2011) standard-errors; $\varrho$ stands for Petersen (2009) standard-errors; $\varpi$ stands for Arellano (1987) standard-errors which is consistent with the information summarized in Table 7

Multi-way clustering was first described by Petersen (2009) and generalized after that in Cameron et al. (2011). Using the formula with the assumptions defined above

$$
\hat{V}_{\text {Double }}=\hat{V}_{\text {Country }}+\hat{V}_{\text {Period }}-\hat{V}_{\text {White }}
$$

where $\quad \hat{V}_{\text {Country }}=\hat{H}^{-1} \sum_{i=1}^{N}\left(\hat{c}_{i} \hat{c}_{i}^{\prime}\right) H^{-1} ; \quad \hat{V}_{\text {Period,l }}=\hat{H}^{-1} \sum_{t=l+1}^{T}\left(\hat{s}_{t} \hat{s}_{t-1}\right) H^{-1}$; $\hat{V}_{W h i t e, l}=\hat{H}^{-1} \sum_{t=l+1}^{N} \sum_{l=1}^{T}\left(\hat{u}_{i t} \hat{u}_{i, t-1}^{\prime}\right) H^{-1}$.

$\hat{V}_{P e r i o d, 0}$ is the traditional formula for clustered SE's by Period. $\hat{V}_{\text {White }}$ is the common OLS SEs robust to arbitrary heteroskedasticity. $\hat{V}_{W h i t e, l}$ and $\hat{V}_{P e r i o d, l}$ correct for persistent common shocks across panels. Based on previous works, Thompson (2011) upgraded the double-clustering with kernel-robust inference to manage business cycle shocks that disappear after some L periods.

$\hat{V}_{\text {Double }, L \mid w}=\hat{V}_{\text {Country }}+\hat{V}_{\text {Period }}+\sum_{l=1}^{L}\left(\hat{V}_{\text {Period }, l}+\hat{V}_{\text {Period }, l}^{\prime}\right)-\hat{V}_{\text {White }}-\sum_{l=1}^{L}\left(\hat{V}_{\text {White }, l}+\hat{V}_{\text {White }, l}^{\prime}\right)$ 
$K_{\text {_ share }}$ and $A_{-}$share panel errors and regressors display similar time and country effects, which is when the double clustering matters the most. By clustering on country, we produce standard-errors and statistics robust to autocorrelated withinpanel disturbances and combining a kernel-based HAC with period clustering we correct for autocorrelated across-panel disturbances (Thompson, 2011). L_share common correlated disturbances are corrected by clustering by period and by country - we use the Petersen (2009) standard-errors. For BTC_share panel double clustering is not required, so we can obtain the right $\beta$ by clustering on country we use the Arellano (1987) standard-errors.

Additionally, we modify the variance-covariance matrix to account for the fact that we use 5-year averages and for the presence of overleverage points. This affects all the dependent variables and is explained in the following sub-sections.

We choose the following lag selection formula, appropriate for the fact that we use 5-year averages.

$$
m(T)=\text { floor }\left[4(T / 100)^{2 / 9}\right]
$$

The Newey and West (1987) kernel smoother function with linearly decaying weights based on HAC inference was employed:

$$
\omega_{\ell}=\frac{\ell}{1+L}
$$

A weighting function is used to control the effects of high leveraged observations on the calculation of the covariance:

$$
\omega_{t}=\left(1-h_{i}\right)^{\frac{-\delta_{i}}{2}}, \quad \delta_{i}=\min \left(4, h_{i} / \bar{h}\right),
$$

where $h_{i}=X_{t}^{\prime}\left(X^{\prime} X\right)^{-1} X_{i}$ are the diagonal components of the $H=X^{\prime}\left(X^{\prime} X\right)^{-1} X^{\prime}, \bar{h}$ is their mean, and $\delta_{i}$ is the exponential discounting factor that is truncated. CribariNeto and da Silva (2011) discuss in detail the effects of these choices and why the $\mathrm{HC}_{4}$ method is better than the bias-correcting $\mathrm{HC}_{2}$ or pseudo-jackknife $\mathrm{HC}_{3}$ to cope with the presence of influential observations.

\subsection{Regressions Results}

In this section we present the results of estimating our equations for growth sources. 
Table 8: Panel robust estimation results

\begin{tabular}{|c|c|c|c|c|}
\hline$X_{t} Y_{t}$ & $\mathrm{~K}_{\text {_share }}(1)$ & L_share $(2)$ & A_share (3) & BTC_share (4) \\
\hline $\operatorname{csh}_{-} g$ & $\begin{array}{c}-0.841^{* * *} \\
(0.211)\end{array}$ & $\begin{array}{c}-0.799^{*} \\
(0.248)\end{array}$ & $\begin{array}{c}-0.26 \\
(0.366)\end{array}$ & $\begin{array}{c}0.321 \\
(0.283)\end{array}$ \\
\hline trade & $\begin{array}{c}-0.45^{* * *} \\
(0.061)\end{array}$ & $\begin{array}{l}-0.225 \\
(0.151)\end{array}$ & $\begin{array}{l}0.413^{*} \\
(0.245)\end{array}$ & $\begin{array}{c}0.51^{* * *} \\
(0.181)\end{array}$ \\
\hline$h c$ & $\begin{array}{c}0.05 \\
(0.067)\end{array}$ & $\begin{array}{c}0.008 \\
(0.054)\end{array}$ & $\begin{array}{c}-0.224^{* *} \\
(0.102)\end{array}$ & $\begin{array}{c}0.116^{* * *} \\
(0.042)\end{array}$ \\
\hline$g w a r$ & $\begin{array}{l}-0.002 \\
(0.074)\end{array}$ & $\begin{array}{l}-0.004 \\
(0.028)\end{array}$ & $\begin{array}{c}0.024 \\
(0.137)\end{array}$ & $\begin{array}{l}-0.011 \\
(0.108)\end{array}$ \\
\hline$p d 1$ & $\begin{array}{l}-0.001 \\
(0.003)\end{array}$ & $\begin{array}{c}0.01 \\
(0.006)\end{array}$ & $\begin{array}{l}-0.002 \\
(0.006)\end{array}$ & $\begin{array}{c}0.017^{* * *} \\
(0.005)\end{array}$ \\
\hline temp & $\begin{array}{c}0.001 \\
(0.005)\end{array}$ & $\begin{array}{c}0.005 \\
(0.003)\end{array}$ & $\begin{array}{c}-0.016^{* * *} \\
(0.006)\end{array}$ & $\begin{array}{l}0.0017 \\
(0.003)\end{array}$ \\
\hline ethnic & $\begin{array}{c}-0.201^{* * *} \\
(0.071)\end{array}$ & $\begin{array}{c}0.296^{* *} \\
(0.091)\end{array}$ & $\begin{array}{r}-0.182 \\
(0.11)\end{array}$ & $\begin{array}{c}0.124 \\
(0.112)\end{array}$ \\
\hline Constant & $\begin{array}{c}0.765^{* * * *} \\
(0.241)\end{array}$ & $\begin{array}{l}0.296^{*} \\
(0.179)\end{array}$ & $\begin{array}{c}1.127^{* * *} \\
(0.397)\end{array}$ & $\begin{array}{c}-0.337^{* *} \\
(0.157)\end{array}$ \\
\hline Wald $\mathcal{F}(7,711)$ & $3.349^{* * *}$ & $2.028^{* *}$ & $2.68^{* * *}$ & $3.097^{* * *}$ \\
\hline Method & Pooled & Random & Pooled & Pooled \\
\hline
\end{tabular}

Note: Regressors are defined in the first column of the Table. Dependent Variables are defined in the first row of the Table. Values in parentheses below the observed coefficients are the Thompson (2011) two-way cluster and kernel-robust SE's (1 and 3), Petersen (2009) two-way clustered-robust SE's (2) and Arellano (1987) one-way cluster-robust SE's (4). Level of significance: $* * *$ for p-value $>0.01,{ }^{* *}$ for $>0.05,{ }^{*}$ for $>0.1$. To reach the results we used $\mathrm{R}$ package $\mathrm{plm}$. For (1) and (3) equations we applying a block building process which was built using the commands vcovSCC and vcovHC. Equation (2) used the command vcovDC and (4) the vcovHC. All 4 equations use Cribari-Neto and da Silva (2011) HC4 weighting function. (1 and 3) and Newey and West (1987) kernel-smother with 2 lags.

From the analysis of Table 8 we can note that the physical capital component is strongly influenced by the government share in the economy as well as by trade and ethnic diversification. This fact indicates a potentially strong crowding-out effect in the long run that can be associated with intertemporal Ricardian effects on the decision of investments when agents expect higher taxes in the future. This also indicates that the usually negative and significant sign of government expenditures on growth regressions may come from the physical capital source of growth. The fact that trade is negatively influencing the physical capital component may be explained by an infant industry argument and an explanation of why openness is not always 
significant in growth regressions. This also has some support in the literature. For example, Madsen (2009) showed that openness is independent of economic growth in much of history but is positively associated with growth when technology is taken into account. This is precisely what our results seem to support, as trade has a positive and highly significant influence on both total factor productivity and biased technical change components of growth. Moreover, economic theory also has shown that in some conditions protectionism may increase welfare (see, e.g. Tuinstra et al. (2014)). Finally, ethnic diversity has a highly detrimental effect on the physical capital component of growth, which is very much consistent with the empirical literature as in Easterly and Levine (1997) and Alesina et al. (2003).

Interestingly, the government share in income has also a negative effect on the labor share, which reinforces our argument toward an intertemporal Ricardian effect in this case on the labor/leisure decisions. Additionally, ethnic diversity appears with a positive effect on the labor component, which highlights its potential positive effect on human capital and labor adaptability on the labor market, which also has some support in recent empirical contributions from Hoogendoorn et al. (2012) and ?. This also indicates that the negative effect that ethnic diversity can have on overall economic growth may come from the investment in physical capital and not in the labor market.

The remaining most important results are the significant negative effect of human capital in the TFP component and positive effect on the BTC component and a positive effect of historical population density in the BTC component. On the one hand, negative effects of human capital in TFP are somewhat unexpected and can be obtained through high duplication effects (see e.g. Jones (1995)), or complexity effects, which may lead to negative scale effects - see, e.g. Sequeira et al. (2018). On the other hand, positive effects of human capital on the biased technical change component is an expected result, as human capital is more adapted to work with new investments and thus contributes to a bias toward capital. Additionally, this can be a direct consequence of the positive effect of human capital in wages of the more qualified, which may lead to an increase in the capital-labor ratio (Acemoglu, 2002, Violante, 2012). The positive effect of historical population density in the biased technical change component is interesting in line with recent evidence that historically determined investments influence today's economic activity (e.g. Dalgaard et al. (2018)). This means that historically, more developed regions or countries tend to favor physical capital nowadays, suggesting a channel through which historical persistence of development can occur, i.e., through biased technical change. Finally higher temperatures seem to decrease TFP, suggesting a channel through which temperature (and climate change in general) may affect growth (as shown by, 
e.g. Dell et al. (2012)). A table that sums up the empirical results in this section is provided in Appendix A.2.

\subsection{Robustness test}

Thompson (2011) suggests double clustering standard-errors in multivariate regression in which some regressors vary by time, and some vary by country. Cameron et al. (2008) propose a wild-cluster bootstrap with a low asymptotic requirement and robust in the presence of heteroskedastic errors. Another popular option is named pairs bootstrap, which resamples. In a financial application, Kayhan and Titman (2007) demonstrate that bootstrap is a viable option to break dependency issues like heterogeneous within-cluster correlation. Cameron and Miller (2015) offer a good overview of cluster-robust methods.

Table 9: Estimation results with wild cluster bootstrap standard errors

\begin{tabular}{|c|c|c|c|c|}
\hline$Y_{t} Y_{t}$ & $\mathrm{~K}_{\text {_share }}(1)$ & L_share (2) & $A_{\text {_share }}(3)$ & BTC_share (4) \\
\hline \multirow{2}{*}{$c s h_{-} g$} & $-0.841^{* * *}$ & $-0.799 * *$ & -0.263 & $0.321^{* * *}$ \\
\hline & $(0.224)$ & $(0.341)$ & $(0.458)$ & $(0.121)$ \\
\hline \multirow{2}{*}{ trade } & $-0.45^{* *}$ & -0.224 & 0.413 & $0.512^{* * *}$ \\
\hline & $(0.035)$ & $(0.169)$ & $(0.302)$ & $(0.05)$ \\
\hline \multirow{2}{*}{$h c$} & 0.05 & 0.008 & $-0.224^{* * *}$ & $0.116^{* * *}$ \\
\hline & $(0.042)$ & $(0.054)$ & $(0.068)$ & $(0.028)$ \\
\hline \multirow{2}{*}{ gwar } & -0.002 & -0.004 & $0.024^{*}$ & -0.011 \\
\hline & $(0.011)$ & $(0.005)$ & $(0.013)$ & $(0.021)$ \\
\hline \multirow{2}{*}{$p d 1$} & -0.001 & $-0.011^{* *}$ & -0.002 & $0.017^{* *}$ \\
\hline & $(0.007)$ & $(0.005)$ & $(0.007)$ & $(0.006)$ \\
\hline \multirow{2}{*}{ temp } & 0.001 & 0.004 & $-0.016 * * *$ & 0.0017 \\
\hline & $(0.003)$ & $(0.005)$ & $(0.004)$ & $(0.002)$ \\
\hline \multirow{2}{*}{ ethnic } & -0.201 & $0.279 * *$ & -0.182 & $0.124^{*}$ \\
\hline & $(0.123)$ & $(0.127)$ & $(0.138)$ & $(0.086)$ \\
\hline \multirow{2}{*}{ Constant } & $0.765 * * *$ & 0.396 & $1.127^{* * *}$ & $-0.337 * * *$ \\
\hline & $(0.147)$ & $(0.238)$ & $(0.208)$ & $(0.086)$ \\
\hline
\end{tabular}

Note: Regressors are defined in the first column of the Table. Dependent Variables are defined in the first row of the Table. Values in parentheses below the observed coefficients are the Cameron et al. (2008) wild bootstrapped multi-way clustered SE's. Level of significance: *** for p-value $>0.01,{ }^{* *}$ for $>0.05,{ }^{*}$ for $>0.1$. The number of replications used was 999 . To reach the results we used the $R$ package $\mathrm{plm}$.

In the robustness results shown in Table 9 most results of Table 8 are maintained. 
For example, the physical capital component is strongly influenced by the government share in the economy and by trade. However, the significant effect of ethnic fractionalization disappears, maintaining its positive and significant effect in the explanation of the labor component and now also with a marginally significantly positive sign in the BTC component. This new effect may suggest that more ethnic diversified regions tend to favor capital in detriment to labor. Another possible explanation consistent with the references cited above is that as ethnic diversification favors the labor share (with an effect on wages), it would contribute to firms replacing labor by capital. The government share now appears with a significant and positive effect

on the contribution of BTC to growth. For instance, Cozzi and Impullitti $(2010)$ argued that government spending played a significant role in stimulating the wave of innovation that hit the U.S. economy in the late 1970s and the 1980s, as well as the simultaneous increase in inequality and education attainments. Thus, this rise of wages may lead the economy to favor physical capital, and thereby increasing the capital to labor ratio, which would help to explain this result.

Trade maintains its highly significant and positive effect on the BTC component, although it loses significance in explaining TFP. The effects of human capital and temperature are maintained. Historical population density appears with an additional significantly negative sign explaining the labor component in growth, which together with the positive sign maintained in the explanation of the BTC component may suggest that the more developed countries in the past rely more today on physical capital than on labor to grow, which is consistent with the historical persistence of development argued by recent research (see again Dalgaard et al. (2018)). Finally, a marginally significant and positive effect of guerrilla warfare on the TFP component can only be explained by the fact that this TFP component cannot be completely associated with technological progress in growth accounting exercises, as it is part of a residual, as is well known in the literature.

\section{Conclusion}

Growth accounting exercises and growth regressions are the most common empirical assessments of the economic growth phenomenon (Barro, 1991, 1997, 1999), one of the main fields of study in macroeconomics. However, those methodologies have been subject to several criticisms. On the one hand, growth accounting often relies on constant shares of the production factors, which seems to be counterfactual, according to very recent evidence. On the other hand, growth regressions are subject to criticisms due to possible endogeneity led by omitted variables, namely common factors (or shocks), heterogeneity, and the presence of outliers. These problems could severely affect the interpretation of the economic growth sources and determinants. 
In this paper, we combine both techniques and address most of the main criticisms raised in the literature. First, we apply a methodology that allows for variable factor shares in growth accounting. Then, we use the growth regression methodology to assess the determinants of each of the components of growth. In this sense, we are going further than most of the previous contributions did in answering the important question: why do some countries grow more than others? We contribute answering to the question: why do some countries rely more on factor accumulation or on technology to grow? Second, we specifically address the features of the data (and specifically, the features of residuals) and account for common shocks, overleverage points, arbitrary heteroskedasticity, within-panel autocorrelation, and cross-panel autocorrelated disturbances in panel data estimations. Overlooking those features has been at the center of the criticisms raised to growth regressions. Thus, we estimate robust panel data regressions to the different factor shares, total factor productivity, and biased technical change components.

The most important evidence reveals that current government expenditure (as a ratio to GDP) decreases the factor shares and has no effect on TFP. Trade, however, positively affects the TFP and the Biased Technical Change (BTC) components, tending to decrease the capital share. Moreover, human capital decreases the TFP contribution but increases the BTC contribution to growth. More deeply rooted determinants of development, such as genetic diversity and historical population density, also affect factor accumulation, TFP, and BTC in different ways. For example, historical population density tends to decrease the contribution of labor but increase the BTC contribution to growth. Additionally, ethnic diversity tends to raise both the labor and the BTC components, but decrease the physical capital component. Finally, the temperature tends to raise the labor share contribution to growth. Looking at the results from a different perspective, capital share decreases due to trade, the government consumption share, and ethnic diversity. Labor share decreases due to the same determinants but increases due to temperature and ethnic diversity. The TFP contribution increases due to trade but decreases due to human capital. Finally, the Biased Technical Change component increases due to trade, human capital, historical population density, and ethnic diversity. Across the different estimation methods, one of the most robust results is the negative effect of government consumption on the shares of factor accumulation.

Interestingly, these results present a good match to the theoretical and empirical literature on economic growth and development, unveiling the channels through which some of the determinants of growth act.

Our paper opens prospects for future research. On the methodological side, it 
offers a new approach based on recently developed econometric methods 15 to deal with critical aspects in growth regressions. On the results side, it highlights that different determinants may explain different sources of growth (production factors and technology), and growth regressions may be misleading when seeking to explain overall growth.

\footnotetext{
${ }^{15}$ Those methods have been applied in other contexts, namely in microeconometrics, but never to approach the economic growth regressions problems.
} 


\section{References}

Acemoglu, D. (2002). Technical Change, Inequality, and the Labor Market. Journal of Economic Literature, 40(1):7-72. 5, 18

Ades, A. and Di Tella, R. (1997). National champions and corruption: some unpleasant interventionist arithmetic. The Economic Journal, 107(443):1023-42. 5

Aisen, A. and Veiga, F. J. (2013). How does political instability affect economic growth? European Journal of Political Economy, 29:151-167. 9]

Alesina, A., Devleeschauwer, A., Easterly, W., Kurlat, S., and Wacziarg, R. (2003). Fractionalization. Journal of Economic Growth, 8(2):155-194. 9, 18

Alesina, A., Osler, S., Roubini, N., and Swagel, P. (1996). Political Instability and Economic Growth. Journal of Economic Growth, 1(2):189-211. 9]

Anselin, L. (2001). Spatial Econometrics. In A companion to theoretical econometrics. Baltagi $B$ (ed), Oxford: Basil Blackwell, pages 310-330. 12

Arellano, M. (1987). Computing Robust Standard Errors for Within-Group Estimators. Oxford Bulletin of Economics and Statistics, 49:431-434. 15, 16, 17

Ashraf, Q. and Galor, O. (2012). Human Genetic Diversity and Comparative Economic Development. American Economic Review, pages 1-73. 9

Banks, A. S. and Wilson, K. A. (2019). Cross-National Time-Series Data Archive. 9. 29,

Barro, R. (1991). Economic Growth in a Cross Section of Countries. The Quarterly Journal of Economics, 106(2):407. 5, 20

Barro, R. (1997). Determinants of Economic Growth: A Cross-Country Empirical Study. Foreign Affairs, 76(6):154. 8, 20

Barro, R. (1999). Notes on Growth Accounting. Journal of Economic Growth, 4(2):119-137. 4, 20

Benhabib, J. y. M. S. (1994). The Role of Human Capital in Economic Development: Evidence from Aggregate Cross-Country Data. Journal of Monetary Economics, 34:143-173. 9 
Bertrand, M., Mullainathan, S., and Duflo, E. (2004). How Much Should We Trust Differences-in-Differences Estimates? Quarterly Journal of Economics, 119(1):249-275. 5

Blanchard, O. (1997). The Medium Run. Brookings Papers on Economic Activity, 2:89-158. 4

Brock, W. A. and Durlauf, S. N. (2001). Growth Empirics and Reality. The World Bank Economic Review, 15(2):229-272. 3

Cameron, A., Gelbach, J. B., and Miller, D. L. (2011). Robust inference with multiway clustering. Journal of Business and Economic Statistics, 29(2):238-249. 15

Cameron, A. and Miller, D. L. (2015). A Practitioner's Guide to Cluster-Robust Inference. Journal of Human Resources, 50(2):317-372. 19

Cameron, A. C., Gelbach, J. B., and Miller, D. L. (2008). Bootstrap-Based Improvements for Inference with Clustered Errors. Review of Economics and Statistics, 90(3):414-427. 2, 7, 19

Caselli, F. and Feyrer, J. (2007). The Marginal Product of Capital. The Quarterly Journal of Economics, 122(2):535-568. 4

Cozzi, G. and Impullitti, G. (2010). Government Spending Composition, Technical Change, and Wage Inequality. Journal of the European Economic Association, 8(6):1325-1358. 20

Cribari-Neto, F. and da Silva, W. B. (2011). A new heteroskedasticity-consistent covariance matrix estimator for the linear regression model. AStA Advances in Statistical Analysis, 95(2):129-146. 3, 16, 17

Dalgaard, C.-J., Kaarsen, N., Olsson, O., and Selaya, P. (2018). Roman Roads to Prosperity: Persistence and Non-Persistence of Public Goods Provision. 18, 20]

Dell, M., Jones, B. F., and Olken, B. A. (2012). Climate Shocks and Economic Growth: Evidence from the Last Half Century. American Economic Journal: Macroeconomics, 4(3):66ß95. 9, 19

Durlauf, S. N. (2005). Complexity and empirical economics. Economic Journal, 115(504). 3

Easterly, W. (2005). Chapter 15 National Policies and Economic Growth: A Reappraisal. In Handbook of Economic Growth, volume 1, pages 1015-1059. 3. 5 
Easterly, W. and Levine, R. (1997). Africa's Growth Tragedy: Policies and Ethnic Divisions. The Quarterly Journal of Economics, 112(4):1203-1250. 9, 18

Easterly, W. and Levine, R. (2003). Tropics, germs, and crops: How endowments influence economic development. Journal of Monetary Economics, 50(1):3-39. 5

Easterly, W. and Levine, R. E. (2001). It's Not Factor Accumulation: Stylized Facts and Growth Models. The World Bank Economic Review, 15(2):177-219. 4

Easterly, W. and Rebelo, S. (1993). Fiscal policy and economic growth. Journal of Monetary Economics, 32(3):417-458. 5

Eberhardt, M. and Teal, F. (2011). Econometrics for grumblers: A new look at the literature on cross-country growth empirics. Journal of Economic Surveys, 25(1):109-155. 2, 11, 12

Feenstra, R. C., Inklaar, R., and Timmer, M. P. (2015). The next generation of the penn world table. American Economic Review, 105(10):3150-3182. 9, 29

Fischer, S. (1993). The Role of Macroeconomic Factors in Growth. National Bureau of Economic Research Working Paper Series, No. 4565. 5

Hall, R. E. and Jones, C. I. (1999). Why do Some Countries Produce So Much More Output Per Worker than Others? The Quarterly Journal of Economics, 114(1):83-116. 4

Hoogendoorn, S., Oosterbeek, H., and Van Praag, M. (2012). Ethnic Diversity and Team Performance: A Randomized Field Experiment. Academy of Management Proceedings, 2012(1):13736. 18

Jones, C. I. (1995). R \& D-Based Models of Economic Growth. Journal of Political Economy, 103(4):759-784. 18

Kaffine, D. T. and Davis, G. A. (2017). A multi-row deletion diagnostic for influential observations in small-sample regressions. Computational Statistics and Data Analysis, 108:133-145. 3

Kahn, J. A. and Lim, J.-S. (1998). Skilled Labor-Augmenting Technical Progress in U. S. Manufacturing. The Quarterly Journal of Economics, 113(4):1281-1308. 4

Kaldor, N. (1961). Capital Accumulation and Economic Growth. The Theory of Capital, pages 177-222. 4 
Kayhan, A. and Titman, S. (2007). Firms' histories and their capital structures. Journal of Financial Economics, 83(1):1-32. 19

Kelly, M. (2019). The Standard Errors of Persistence. SSRN Electronic Journal. 3

Keynes, J. M. (1939). Relative Movement of Real Wages and Output. The Economic Journal, 49(193):34-51. 4

Krueger, A. B. (1999). Measuring labor's share. American Economic Review, $89(2): 45-51.4$

Levine, R. (1997). Financial Development and Economic Growth : Views and Agenda. Journal of Economic Literature, XXXV(June):688-726. 5

Levine, R. (2005). Finance and Growth: Theory and Evidence. chapter 12. 5

Ley, E. and Steel, M. F. J. (2009). On the effect of prior assumptions in Bayesian model averaging with applications to growth regression. Journal of Applied Econometrics, 24(4):651-674. 3

Madsen, J. B. (2009). Trade Barriers, Openness, and Economic Growth. Southern Economic Journal, 76(2):397-418. 18

Majid, N. (2004). What is the effect of trade openness on wages ? International Labour Office. 9

Mallick, S. K. and Sousa, R. M. (2017). The Skill Premium Effect of Technological Change: New Evidence from the US Manufacturing Sector. International Labour Review, pages 113-131. 5

Millo, G. (2017). Robust Standard Error Estimators for Panel Models: A Unifying Approach. Journal of Statistical Software, 82(3). 3

Moscone, F. and Tosetti, E. (2010). Testing for error cross section independence with an application to US health expenditure. Regional Science and Urban Economics, 40(5):283-291. 12

Nakamura, E., Sergeyev, D., and Steinsson, J. (2017). Growth-rate and uncertainty shocks in consumption: Cross-country evidence. American Economic Journal: Macroeconomics, 9(1):1-39. 2 
Newey, W. K. and West, K. D. (1987). A Simple, Positive Semi-Definite, Heteroskedasticity and Autocorrelation Consistent Covariance Matrix. Econometrica, 55(3):703. 16, 17

Nordhaus, W. D. (2006). Geography and macroeconomics: new data and new findings. Proc. Natl Acad. Sci. USA, 103:3510-3517. 9, 29

Petersen, M. A. (2009). Estimating standard errors in finance panel data sets: Comparing approaches. Review of Financial Studies, 22(1):435-480. 2, 7, 15, 16, 17

Pritchett, L. and Aiyar, Y. (2015). Taxes: Price of Civilization or Tribute to Leviathan. SSRN Electronic Journal, pages 1-20. 8

Reinhart, C. M. and Rogoff, K. S. (2010). Growth in a time of debt. American Economic Review, 100(2):573-578. 8

Rousseeuw, P. and Leroy, A. (2003). Robust regression and outlier detection. WileyInterscience, New York. 13

Sala-i Martin, X. (1997). I Just Ran Two Million Regressions. American Economic Review, 87(2):178-183. 2, 3

Sequeira, T., Gil, P. M., and Afonso, O. (2018). Entropy and Endogenous Growth. Journal of Economic Behavior and Organization, 154:100-120. 8, 18

Solow, R. M. (1956). A contribution to the theory of economic growth. The Quarterly Journal of Economics, 70(1):65-94. 2

Solow, R. M. (1957). Technical Change and the Aggregate Production Function. The Review of Economics and Statistics, 39(3):312. 4

Sturgill, B. (2012). The relationship between factor shares and economic development. Journal of Macroeconomics, 34(4):1044-1062. 5

Sturgill, B. (2014). Back to the basics: Revisiting the development accounting methodology. Journal of Macroeconomics, 42:52-68. 4

Sunde, U. and Vischer, T. (2015). Human capital and growth: Specification matters. Economica, 82(326):368-390. 9

Teixeira, A. A. and Queirós, A. S. (2016). Economic growth, human capital and structural change: A dynamic panel data analysis. Research Policy, 45(8):16361648. 9 
Thompson, S. B. (2011). Simple formulas for standard errors that cluster by both firm and time. Journal of Financial Economics, 99(1):1-10. 2, 3, 7, 15, 16, 17, 19

Tuinstra, J., Wegener, M., and Westerhoff, F. (2014). Positive welfare effects of trade barriers in a dynamic partial equilibrium model. Journal of Economic Dynamics and Control, 48. 18

Verardi, V. and Croux, C. (2009). Robust regression in Stata. Stata Journal, $9(3): 439-453.13$

Violante, G. L. (2012). Skill-biased Technical Change. The New Palgrave Dictionary of Economics, 2012 Version. 18

Yanikkaya, H. (2003). Trade openness and economic growth: A cross-country empirical investigation. Journal of Development Economics, 72(1):57-89. 9

Zuleta, H. (2008). An empirical note on factor shares. Journal of International Trade and Economic Development, 17(3):379-390. 4

Zuleta, H. (2012). Variable factor shares, measurement and growth accounting. Economics Letters, 114(1):91-93. 6

Zuleta, H. and Sturgill, B. (2015). Getting Growth Accounting Right. SSRN Electronic Journal. 5,6 


\title{
Appendix A. Countries and Variables Definitions and Sources
}

\author{
Appendix A.1. List of Countries
}

Australia; Argentina; France; Georgia; Mozambique; Kenya; Niger; Benin; Armenia; Cote d'Ivoire; Sierra Leone; New Zealand; Tajikistan; Central African Republic; China; Austria; United Kingdom; Taiwan; Panama; Poland; Croatia; Colombia; Azerbaijan; Japan; Greece; Peru; South Africa; Guatemala; Costa Rica; Bulgaria; Honduras; Lebanon; Sudan; Denmark; Kazakhstan; Czech Republic; Burkina Faso; Philippines; Burundi; Uruguay; Belarus; Israel; Dominican Republic; Cameroon; Nicaragua; Bolivia; Paraguay; Italy; Serbia; Ecuador; Canada; Guinea; United States; Portugal; Romania; Switzerland; Germany; Chad; Russian Federation; Belgium; Rwanda; Singapore; Senegal; Hong Kong; Chile; Ukraine; Netherlands; Saudi Arabia; Slovakia; Turkey; Indonesia; Egypt; Togo; Finland; Tanzania; Jordan; Mexico; Iraq; Hungary; Spain; Kyrgyzstan; Venezuela; Laos; Mongolia; Kuwait; Iran; Sweden; India; Zimbabwe; Malaysia; Nigeria; Lithuania; Ireland; Tunisia; Thailand; Brazil; Jamaica; Norway; Sri Lanka; South Korea; Morocco.

\section{Appendix A.2. Variables Sources and References}

Table Appendix A.1: Variables, Sources and References

\begin{tabular}{ccc}
\hline Regressors & Label & \multicolumn{1}{c}{ Source } \\
\hline Government current expenditure & csh_g & Feenstra et al. $([2015)$ \\
Openness measure & trade & Feenstra et al. $(2015)$ \\
Human capital per person & hc & Feenstra et al. $(2015)$ \\
Guerrila warfare & gwar & Banks and Wilson $(2019)$ \\
Population density in 1 CE & pd1 & Nordhaus $(2006)$ \\
Temperature & temp & Nordhaus \\
Ethnic diversity & ethnic & Nordhaus \\
\hline
\end{tabular}


Table Appendix A.2: Results sum up

\begin{tabular}{lllll}
\hline Determinants & $k$ & $l$ & $a$ & $b t c$ \\
\hline csh_g $_{\text {trade }}$ & - & - & & + \\
hc & - & & & + \\
gwar & & & - & + \\
pd1 & & & & \\
temp & & - & & + \\
ethnic & & & - & \\
\hline
\end{tabular}

